\title{
A COMUNICAÇÃO INSTANTÂNEA POR DISPOSITIVOS MÓVEIS COMO SUPORTE PEDAGÓGICO NO PROCESSO DE ENSINO E APRENDIZAGEM
}

\author{
INSTANT COMMUNICATION BY MOBILE DEVICES AS A \\ PEDAGOGICAL SUPPORT IN THE TEACHING AND LEARNING \\ PROCESS
}

DOI: http://dx.doi.org/10.5965/1984317815012019008

Lúcio França Teles

Universidade de Brasília teleslucio@gmail.com

Tereza Cristina Rodrigues Miranda

Universidade de Brasília tereza.crm@gmail.com

\section{RESUMO}

Este artigo relata resultados de uma pesquisa sobre o uso de mensagens eletrônicas instantâneas no processo de ensino e aprendizagem por professores do ensino médio. A pergunta investigada foi: Quais são as vantagens e os desafios apresentados por professores que utilizam o aplicativo WhatsApp como suporte pedagógico? A fundamentação teórica se encontra em autores que investigam o uso da tecnologia na educação (CASTELLS, 2013; JENKINS, 2009; LEMOS, 2013; LÉVY, 1999). Para estes pesquisadores, a introdução acelerada da tecnologia digital em todas as áreas e, em particular na educação, está afetando a forma como aprendemos e aplicamos nosso conhecimento. Segundo estes autores, o acesso à informação, conhecimento e à comunicação permite avanços sem precedentes no processo de conhecimento. Este é um estudo qualitativo (CRESWELL, 2010) de corte descritivo-interpretativo, que faz uso de técnicas de coleta de dados como questionários, entrevista semiestruturada e seleção dos participantes da pesquisa com a técnica de amostragem bola de neve (BALDIN e MUNHOZ, 2011). Foi aplicado um questionário online que teve 105 respondentes. Posteriormente 10 professores foram entrevistados. Foram identificadas sete dimensões vantajosas na utilização do WhatsApp no processo educativo e cinco dimensões que são obstáculos e dificuldades. A conclusão indica que quando há engajamento, preparação e planejamento docente, a comunicação instantânea por meio do aplicativo em questão tem potencial para tornar-se aliado de práticas pedagógicas exitosas.

Palavras-chave: Tecnologia Educacional; Comunicação Instantânea; WhatsApp; Aprendizagem online; Redes Sociais.

\section{ABSTRACT}

This article reports results of a research on the usage of instant electronic messages in the teaching and learning process by high school teachers. The question asked was: What are the advantages and challenges presented by teachers who use WhatsApp app as pedagogical support? The theoretical basis is found in authors who investigate the use of technology in education (CASTELLS, 2014; JENKINS, 2009; LEMOS, 2013; LÉVY, 1999). For these researchers, the accelerated introduction of digital technology in all areas, and particularly in education, is affecting how we learn and apply our knowledge. According to these authors, access to information, knowledge and communication allows unprecedented advances in the knowledge process. This is 
a qualitative research (CRESWELL, 2010) descriptive-interpretative, which makes use of data collection techniques such as questionnaires, semi-structured interview and selection of the participants of the research with the technique of snowball sampling (BALDIN and MUNHOZ, 2011). An online questionnaire was applied and had 105 respondents. Subsequently 10 teachers were interviewed. It was identified seven advantageous dimensions in the use of WhatsApp in the educational process as well as five dimensions that are obstacles and difficulties. The conclusion is that when there is engagement, preparation and teacher planning, instant communication has the potential to become an ally of successful pedagogical practices.

Keywords: Education Technology; Instant Communication; WhatsApp; Online Learning; Social Networks.

\section{INTRODUÇÃO}

Este estudo traz relatos e reflexões sobre experiências de professores que enfrentam o medo do desconhecido, a insegurança de trabalhar com novidades trazidas pelos próprios alunos e, principalmente, educadores que desfrutam das vantagens de se adaptar a uma realidade que se modifica a cada dia e em velocidade que inviabiliza qualquer plano detalhado de ação a longo prazo.

O recorte desta pesquisa incide no uso pedagógico das formas de se comunicar e de acessar informações que, nos últimos anos, estão sendo propiciadas pelas mensagens eletrônicas instantâneas enviadas por meio de dispositivos móveis. É notório que os aparelhos celulares vêm ocupando um papel de grande relevância nas relações sociais. Deixaram de ser um meio de apenas telefonar para atender a outras formas de comunicação. Há também um grande número de profissionais que os consideram recursos agregadores para as práticas pedagógicas.

No livro Polegarzinha, o filósofo francês Michel Serres discorre sobre a geração que digita os textos e tem acesso à informação por meio dos polegares. São jovens que vivem conectados em rede sem sair do lugar: "por celular, têm acesso a todas as pessoas; por GPS, a todos os lugares; pela internet, a todo o saber" (SERRES, 2015, p. 19). 


\section{CONTEXTUALIZAÇÃO DO PROBLEMA}

"O uso de uma tecnologia pode enriquecer a mente humana, engrandecer o espírito, libertá-lo, intensificar sua vida interior."

(Walter Ong)

Temos acompanhado, nos últimos anos, mudanças importantes na forma como os aparatos tecnológicos - e, de modo geral, a evolução nas formas de se comunicar e de acessar informações - influenciam os processos de ensino e aprendizagem em ambientes escolares. Percebe-se que movimentos como a democratização do acesso à internet e a popularização dos dispositivos móveis têm aumentado os modos de interação entre alunos e professores (SANTOS, 2011).

Aqui procura-se identificar, entre as várias formas de auxílio que as ferramentas tecnológicas têm oferecido no campo pedagógico, algumas que apresentam relevância e facilidade de uso. O aplicativo WhatsApp, um dos mais populares do mundo, é visto como importante aposta nesse sentido, pois tem facilitado a interação entre grupos de alunos e professores, além de trazer recursos e conteúdos originais para as salas de aula (LOPES, 2016; SILVA, SILVA e RIBEIRO, 2015).

Uma das grandes vantagens do uso do WhatsApp é referente ao custo, pois os serviços são gratuitos, não há cobranças de tarifa anual, sendo necessária apenas conexão com a internet para viabilizá-lo - o que pode ser feito de qualquer lugar.

Profissionais de diferentes áreas defendem o WhatsApp como ferramenta de comunicação rápida e promissora a ser utilizada como plataforma de apoio à educação. Moran (2015) destaca, de forma positiva, as facilidades proporcionadas pelo aplicativo, que estimula a utilização de uma linguagem mais familiar, com maior espontaneidade e fluência constante de imagens, ideias e vídeos.

O uso do WhatsApp como recurso pedagógico tem sido explorado por estudiosos da área (BOTTENTUIT JUNIOR, ALBUQUERQUE, 2016; MORAN, 2015). Diferentes tipos de abordagens são usados para examinar o modo como o aplicativo está sendo aproveitado por 
professores em suas práticas cotidianas ou em atividades específicas. Há diversos artigos acadêmicos publicados que relatam experiências exitosas sobre formas de apreensão da ferramenta, explicando principalmente como ela foi usada, que situações foram propícias ou não e os resultados gerados (HONORATO e REIS, 2014; PEREIRA e ARAÚJO, 2015; BARCELLOS, 2015). No entanto, permanece merecendo apuração mais detalhada a representatividade de mudanças como esta para a comunidade escolar.

\section{FUNDAMENTAÇÃO TEÓRICA: CONVERGÊNCIAS MIDIÁTICAS E NOVOS SABERES}

O século $X X$ foi prodigioso em diversas áreas, e na educação, bem como na comunicação, não foi diferente. Pierre Lévy (1999) acredita que, da revolução industrial à revolução eletrônica, a cultura contemporânea tem sido construída a partir dessas modificações. O que chamamos hoje de cibercultura foi definido pelo autor como o conjunto de técnicas, práticas, atitudes, modos de pensamento e valores que se desenvolvem juntamente com o crescimento do ciberespaço.

Adaptar a realidade escolar às rápidas transformações culturais que se processam na contemporaneidade é, portanto, um desafio constante. No entanto, a escola não pode se abster de trazer para o seu meio o que acontece à sua volta, já que as ferramentas tecnológicas, especialmente quando conectadas à internet, transformam não só as maneiras de se comunicar, mas também de estudar, trabalhar, inserir-se na sociedade enfim. Para Lévy (1999), as tecnologias utilizadas como recursos didáticos redefinem a função docente e agregam às práticas de ensino e aprendizagem novos modos de acesso aos conhecimentos.

Fica evidente, portanto, que o papel do professor está mudando. Mesmo que não se sinta preparado para tal, ele é cada vez mais levado a se comunicar não só face a face com seus alunos, mas também digitalmente, interagindo em modos de ensinar que tendem a se hibridizar.

Os dispositivos móveis com acesso à internet deixaram de ser privilégio de poucos e, em razão disso, cada vez mais as pessoas estão se comunicando com mais facilidade em tempo real. A edição da pesquisa TIC Domicílios divulgada em setembro de 2016 pelo Centro de Estudos sobre as Tecnologias da Informação e da Comunicação (CETIC.BR, 2016) mostra que $51 \%$ dos domicílios brasileiros têm acesso à internet. São 34,1 milhões de lares conectados. Ao todo, $89 \%$ dos brasileiros conectados acessam a rede pelo celular, percentual 
bem maior do que os que a acessam pelo computador (69\%). Os dados da Agência Nacional de Telecomunicações (Anatel), de dezembro de 2016, indicam que há 244,1 milhões de celulares no Brasil. Uma incrível densidade de 118,04 aparelhos para cada 100 habitantes (ANATEL, 2016).

Jenkins (2009), na introdução do livro Cultura da Convergência, diz que nenhum de nós pode saber tudo, cada um de nós sabe alguma coisa, e podemos juntar as peças, se associarmos nossos recursos e unirmos nossas habilidades. "A inteligência coletiva pode ser vista como uma fonte alternativa de poder midiático" (Idem, 2009, p. 30).

Para o autor, os múltiplos usos dos celulares são um fato representativo do período que estamos vivenciando, caracterizado pela fragmentação do conteúdo em diversos meios de comunicação. O autor exemplifica que o indivíduo pode emitir e receber informações em tempo real para e de qualquer parte do planeta e que, por isso, a convergência não é apenas das tecnologias, mas sim da cultura e do modo de agir em sociedade. "Os consumidores são incentivados a procurar novas informações e fazer conexões em meio a conteúdos de mídia dispersos." (Idem, 2009, p. 30)

Pesquisadores como Silva e Teles (2016) enxergam as redes sociais como meios que possibilitam a efetividade da aprendizagem colaborativa capazes, inclusive, de ultrapassar as possibilidades pedagógicas:

Busca-se pensar as redes sociais como um dos meios em que a aprendizagem colaborativa acontece, entretanto, entende-se que, para além de uma aprendizagem restrita aos conteúdos tradicionais do currículo escolar, podem avançar para a compreensão de uma possibilidade de formação ampla e participação social e política (SILVA \& TELES; 2016, p. 2).

De acordo com Nagumo e Teles (2016), a dinâmica social resultante do uso massivo de telefonia celular criou uma mudança de paradigma na natureza das interações humanas. Os autores explicam que com o uso cada vez mais comum desses aparelhos, é inevitável a ampliação da presença dos celulares na escola. "Os jovens estão desenvolvendo novas normas e competências sociais que são especificamente direcionadas a vivências nas redes sociais, tais como a forma de articular amizades, como ser educado na companhia de seus pares..." (Idem, 2016, p. 365) 
Entre os aplicativos de tempo real, o WhatsApp, na mesma linha de outras redes sociais digitais, tem linguagem própria. São comuns as conversas com redução gráfica de palavras. Algumas expressões foram criadas para tal ou somente são usadas neste meio. Além de ser recorrente o uso de imagens - especialmente os tão popularizados emoticons, as carinhas desenhadas que costumam substituir expressões como tristeza, alegria, sono, choro, emoção etc.

Mesmo não se atendo ao estudo de tal linguagem, esta pesquisa registra a criatividade e irreverência como características que ampliam a capilaridade da rede social. Ao atrair os jovens, o modo de comunicação proporcionado cumpre mais do que seu papel de transmitir informações: torna tal comunicação objeto de desejo e de troca de experiências. Isso certamente contribuiu para o sucesso do WhatsApp entre o público jovem e o ajudou a se tornar tão popular entre grupos escolares.

\section{PERGUNTA DA PESQUISA}

A pergunta investigada neste estudo é "Quais são as vantagens e os desafios apresentados por professores que utilizam o aplicativo WhatsApp como suporte pedagógico?"

Dessa forma, o objetivo geral é investigar experiências de professores que utilizam o WhatsApp como ferramenta pedagógica, as quais revelem as diferentes maneiras que elas podem ocorrer, suas vantagens e desvantagens. Sendo que entre os objetivos específicos estão gerar relatos dos usos didáticos do aplicativo e realizar a descrição e interpretação dos mesmos.

\section{METODOLOGIA QUALITATIVA}

Nesta pesquisa foi utilizada metodologia qualitativa com a aplicação das seguintes técnicas de coleta de dados: a) amostragem bola de neve; b) questionário online; e c) entrevistas semiestruturadas. Estes instrumentos foram utilizados para identificar professores interessados em participar do levantamento. Desta forma, com auxílio de um questionário online e de entrevistas semiestruturadas, este trabalho buscou respostas de docentes de diferentes escolas, cidades ou regiões do país, por 
meio de mensagens que foram espalhadas entre pessoas conhecidas e colaboradores voluntários, que foram convidados a repassá-las a outros professores, em uma técnica denominada amostragem bola de neve.

Também chamada snowball sampling, esta técnica . uma forma de amostra não probabilística utilizada em pesquisas sociais nas quais os primeiros participantes indicam novos participantes que, por sua vez, indicam outros, e assim sucessivamente, até que seja alcançada a meta proposta.

De acordo Baldin e Munhoz (2011), para que se tenha uma amostra considerável, o ideal é que seja planejado um número inicial de pessoas que, de preferência, exerçam papel de liderança no espaço a ser estudado. No caso desta pesquisa, foi possível perceber que o engajamento de professores que se interessam pelo uso de tecnologias em salas de aula, em muitos casos, chega a ser suficiente para torná-los uma espécie de líderes nas escolas em que atuam. E, por isso, a técnica funcionou de maneira sistemática.

Outro ponto a ser destacado sobre a amostragem bola de neve refere-se à heterogeneidade permitida nos resultados. Por meio dela, é possível obter respostas de uma grande diversidade de sujeitos.

Para interpretar os dados coletados, foram utilizados os princípios da análise de conteúdo apresentada por Bauer (2002). O autor indica a classificação das informações colhidas nas experiências realizando junção de reflexões teóricas e práticas. Ele sugere uma leitura atenta de todo material para escolher as ênfases que serão dadas e, em seguida, categorizar e fazer possíveis conexões entre o material conseguido e a finalidade da pesquisa. "A teoria e o problema - que carregam em si os preceitos do pesquisador - serão responsáveis pela seleção e categorização dos materiais de texto, tanto implícita quanto explicitamente" (Idem, 2002, p. 195).

Para a coleta de dados, recorreu-se, primeiramente, a um questionário e, em seguida, a entrevistas com um grupo de professores. A aplicação do questionário foi realizada através do Formulário Google, também conhecido como Google Forms. As perguntas foram previamente enviadas para a validação de três professores que atuam em escolas do Distrito Federal e que se dispuseram a fazer testes para o aperfeiçoamento do questionário. Direcionado a professores que se interessam pelo tema, o questionário continha, ao todo, nove perguntas, sendo cinco de múltipla escolha, três questões dissertativas e uma sobre o 
perfil do participante. Os convites para responder e ajudar a divulgar o questionário foram, surpreendentemente, bem recebidos.

Uma vez que este estudo buscou investigar de que maneiras o WhatsApp pode ser usado de forma didática em atividades escolares e quais as vantagens e os principais desafios vivenciados por quem utiliza o recurso, entende-se que o detalhamento desses usos pelos professores se faz necessário para alcançar os objetivos. Por isso, recorreu-se também a entrevistas.

Dos 15 convites enviados para possíveis entrevistados, 10 tiveram retornos positivos para participar da pesquisa. No cruzamento feito entre as respostas dadas por estes 10 professores no questionário online e na entrevista, pôde-se perceber que o segundo instrumento complementou de forma eficaz as informações obtidas no primeiro.

Todas as 10 conversas foram gravadas com o auxílio de um aplicativo de áudio no celular e, em sua essência, transcritas. O objetivo, com isso, foi alcançar um maior entendimento do contexto: além das palavras em si, também se complementou a análise com as entonações de voz e as pausas, por exemplo. Como sugere Gaskell: "ao ler as transcrições, são relembrados aspectos da entrevista que vão além das palavras e o pesquisador quase revive a entrevista. Esta é uma parte essencial do processo e é por isso que é muito difícil analisar entrevistas feitas por outras pessoas” (2002, p. 85).

\section{ANÁLISE DE DADOS E RESULTADOS}

Aqui discutimos a apresentação e análise dos dados coletados por meio do questionário online, respondido por 105 professores de diferentes regiões brasileiras e realidades diversas de estruturas e metodologias de ensino. Os resultados das entrevistas também são apresentados, particularmente no que elas expandem e esclarecem mais as respostas do questionário. Se tratam de entrevistas realizadas com 10 professores que correspondem ao perfil da busca por detalhamento no presente estudo. Houve 40 homens e 60 mulheres participantes dentre as 100 respostas consideradas válidas, mas é importante destacar que algumas respostas não foram computadas por estarem incompletas. 
Tabela 1 - Faixa etária do total de participantes

\begin{tabular}{|c|c|c|}
\hline \multicolumn{1}{|c|}{ Idade } & Número & $\%$ \\
\hline 20 a 30 anos & 13 & 14,3 \\
\hline 30 a 40 anos & 38 & 41,7 \\
\hline 40 a 50 anos & 28 & 30,8 \\
\hline Mais de 50 anos & 12 & 13,2 \\
\hline
\end{tabular}

Fonte: dos autores. 2016.

Os resultados dos questionários e das entrevistas foram agrupados em categorias nos quadros 1 e quadro 2 . A seguir estes quadros são discutidos e apresentados para ilustrar as categorias identificadas.

Outro tópico que merece destaque no questionário é que a maioria dos participantes desta etapa da pesquisa trabalha em escolas públicas (48 pessoas, ou $70 \%$ ). Em um total de 69 respostas, 16 dão aulas em escolas privadas, o que corresponde a 23\%. Os professores que trabalham em escolas públicas e privadas (5) correspondem a 7\%.

Estes números desmistificam a percepção - bastante comum - de que as escolas públicas oferecem pouco estímulo para que os professores lancem mão de recursos tecnológicos, como os celulares com acesso à internet, para trabalhar com seus alunos. Sem generalizar, os resultados mostraram também ser considerada equivocada a percepção de que são os professores da área de ciências humanas os que mais utilizam o aplicativo WhatsApp com seus alunos. O Gráfico 1 mostra, no entanto, a diversidade das áreas de formação ou atuação dos respondentes do questionário. Destaca-se que alguns participantes não especificaram com quais disciplinas trabalham. Os que explicitaram a área de formação foram contabilizados a seguir, com um total de 87 respostas. 
Gráfico 1- Áreas de formação e/ou atuação dos respondentes do questionário

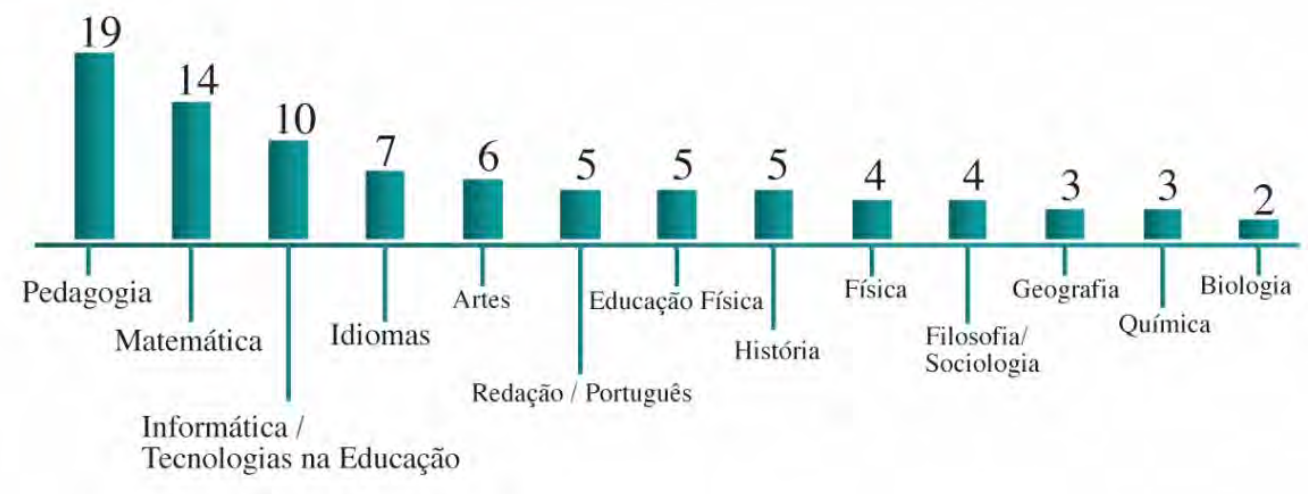

Fonte: dos autores. 2016.

A questão sobre se o WhatsApp é um aplicativo comum no seu ambiente de trabalho foi respondida por 100 pessoas, sendo 87 respostas positivas e 13 negativas.

Quando perguntado sobre se teve alguma experiência em que o uso do WhatsApp tenha colaborado para a aprendizagem de seus alunos, 60 dos 100 participantes responderam. Algumas dessas respostas são citadas abaixo. Na análise de dados, optou-se por se referir a eles por letras (Professor A, Professor B etc.), de acordo com a ordem alfabética dos nomes verdadeiros.

O aplicativo permite socializar informações coletadas pelo grupo e levantar questionamentos acerca dessas mesmas informações. Assim todos são incluídos nas pesquisas de todos (PROFESSOR E, 2016).

Uso para tirar dúvidas dos alunos, socializar textos, imagens etc. Receber ou enviar atividades. Além da orientação de pequenos grupos de trabalho (PROFESSOR G., 2016)..

Estes depoimentos são uma mostra das várias possibilidades de uso do WhatsApp como ferramenta pedagógica. 
Foram também coletados dados sobre as vantagens didáticas deste aplicativo (Quadro 1). Os autores da pesquisa identificaram e agruparam sete características que os professores percebem como vantajosas no uso do WhatsApp: I. Atratividade, II. Colaboração, III Continuidade, IV. Baixo Custo, V. Estímulo, VI. Instantaneidade, VII. Oportunidade. Da mesma forma, foram ainda identificadas e agrupadas cinco características da utilização do WhatsApp na didática da sala de aula que podem ser dificuldades ou desafios que o professor deve levar em conta no uso da tecnologia: VIII. Aumento das Atividades, VII. Conectividade, X. Inovação, XI. Dispersão, XII. Informalidade (Quadro 2). Tal sistematização foi elaborada pelos pesquisadores, em etapa posterior às conversas com os respondentes.

Quadro 1 - Vantagens do WhatsApp para o professor

\begin{tabular}{|c|c|}
\hline I. Atratividade & $\begin{array}{l}\text { - Os alunos podem receber conteúdos em formatos que não } \\
\text { são só textos, mas também áudios, vídeos e fotos } \\
\text { professor traz e pode se tornar um bate-papo contínuo } \\
\text { - } \quad \text { É fácil e simples fazer foto de uma página de um livro ou de } \\
\text { uma atividade resolvida e enviar pelo aplicativo }\end{array}$ \\
\hline II. Colaboração & $\begin{array}{l}\text { - Rede de aprendizagem: em grupos de WhatsApp, os alunos } \\
\text { se ajudam mais, trocam dicas e se tornam mais solidários } \\
\text { - } \quad \text { Ao tirar a dúvida de um aluno, o professor pode responder o } \\
\text { que era dúvida de outros participantes do grupo } \\
\text { O aplicativo aproxima as pessoas com interesses em comum } \\
\text { e aumenta a interação entre colegas } \\
\text { - Na formação de grupos para apresentar trabalhos, dá para o } \\
\text { professor participar e saber, por exemplo, se todos estão colaborando }\end{array}$ \\
\hline III. Continuidade & $\begin{array}{l}\text { Permite compartilhar as atividades trabalhadas em sala de } \\
\text { aula com os alunos que faltaram } \\
\text { - } \quad \text { As discussões e debates começam no WhatsApp e depois vão } \\
\text { para a sala de aula ou vice-versa } \\
\text { - Organização das atividades extraclasse }\end{array}$ \\
\hline IV. Baixo Custo & $\begin{array}{l}\text { - Quem tem internet no celular fala de graça com outros } \\
\text { usuários do aplicativo } \\
\text { - } \quad \text { WhatsApp muitas vezes evita o desperdício de material, } \\
\text { energia e tempo, pois requer pouca estrutura e não exige espaço físico }\end{array}$ \\
\hline
\end{tabular}




\begin{tabular}{|c|c|}
\hline & - $\quad$ O envio de recados por grupos evita que se imprima papel \\
\hline V. Estímulo & $\begin{array}{l}\text { - } \\
\text { - } \quad \text { Facilita o aprendizado o sentimento de pertencimento } \\
\text { - } \quad \text { Mais alunos fazem a tarefa, já que o aplicativo pode funcionar } \\
\text { como um lembrete diário } \\
\text { - } \quad \text { Há mais compartilhamento de descobertas, dúvidas e ideias } \\
\text { nã uma nova forma de socialização: inclui pessoas que talvez } \\
\text { não participassem de uma conversa presencial }\end{array}$ \\
\hline VI. Instantaneidade & $\begin{array}{l}\text { - É rápido, dinâmico, prático e ágil } \\
\text { Permite feedback imediato e a comunicação em tempo real } \\
\text { (bem mais rápido do que uma troca de e-mails, por exemplo) } \\
\text { E É fácil fazer e desfazer grupos para tirar dúvidas sobre } \\
\text { determinados temas ou para uma atividade específica }\end{array}$ \\
\hline VII. Oportunidade & $\begin{array}{l}\text { - O aplicativo está popularizado, é fácil de entender e de } \\
\text { manusear } \\
\text { - } \quad \text { É possível trabalhar com um público grande, bem maior que o } \\
\text { - São inúmeras as possibilidades de atividades e a diversidade } \\
\text { de conteúdos que podem ser enviados } \\
\text { - Amplia o alcance do ensino: a mobilidade permite trabalhar de } \\
\text { qualquer lugar e com grupos cujos membros estejam distantes } \\
\text { fisicamente } \\
\text { - É um espaço para debate com a linguagem que os alunos } \\
\text { gostam de usar } \\
\text { Aproxima o aprendizado formal do informal }\end{array}$ \\
\hline
\end{tabular}

Fonte: dos autores 2016.

Estas características são associadas às vantagens do uso do aplicativo WhatsApp como suporte didático com turmas de estudantes do ensino médio. Algumas destas características como a facilitação do processo de Colaboração são mencionadas por vários professores. 
Uso para envio de apostilas e exercícios. Como é o grupo da sala de aula, no momento de resolver as atividades, as dúvidas são postadas e há uma interação entre os alunos mutuamente, inclusive comigo ajudando nas resoluções ou, posteriormente, auxílio nas dúvidas que não foram resolvidas no momento (PROFESSOR D, 2016).

Uma outra característica também comumente citada é o Baixo Custo. O aplicativo WhatsApp foi conquistando seus usuários também pelo baixo custo que representa no cotidiano de milhares de pessoas que passaram a se comunicar por mensagens eletrônicas instantâneas quando, antes, precisavam fazer ligações telefônicas pagas. O Professor $\mathrm{F}$ disse ter começado a usar o aplicativo por causa de amigos que comentavam sobre o assunto e, na época, estavam montando grupos de conversa: "[...] Eu achei bom por ser mais barato do que utilizar mensagens de texto e ligações" (PROFESSOR F, 2016).

Estas características favorecem o uso crescente do aplicativo WhatsApp por professores como recurso de comunicação, interação, acesso à informações, e resolução de problemas em atividades com seus alunos.

Por outro lado, neste estudo foram também identificadas aquelas características que se apresentam como negativas para o professor usuário do WhatsApp como recurso didático:

Quadro 2 - Desafios da utilização do WhatsApp como suporte didático

\begin{tabular}{|c|c|}
\hline $\begin{array}{c}\text { VIII. Aumento } \\
\text { das atividades }\end{array}$ & $\begin{array}{r}\text { - Gerir grupos de WhatsApp requer atenção constante } \\
\text { É preciso administrar o tempo para ler muitas mensagens, que } \\
\text { chegam em diferentes horários e dias da semana }\end{array}$ \\
$\begin{array}{c}\text { - Alguns casos exigem planejamento específico para atividades } \\
\text { trabalhadas com o aplicativo }\end{array}$ \\
$\begin{array}{c}\text { IX. } \\
\text { Conectividade }\end{array}$ \\
$\begin{array}{c}\text { - Muitas escolas proíbem o uso de celular ou o acesso ao wi-fi } \\
\text { da escola }\end{array}$
\end{tabular}




\begin{tabular}{|c|c|}
\hline & $\begin{array}{l}\bullet \text { Os alunos gostam de acessar a internet e mexer no celular, mas } \\
\text { quando é para atividades, alguns reclamam ou apresentam dificuldade }\end{array}$ \\
\hline X. Inovação & $\begin{array}{l}\text { - Como em muitos casos não há orientação para trabalhar } \\
\text { pedagogicamente com o WhatsApp, cada professor precisa descobrir o } \\
\text { melhor modo de funcionamento de cada grupo } \\
\text { - Ter "domínio" das atividades não é fácil em um ambiente virtual } \\
\text { horizontalizado como se propõe a ser o WhatsApp } \\
\text { - É necessário não ter medo de enfrentar desafios novos que } \\
\text { podem surgir com o uso pedagógico de tecnologias } \\
\text { - Manter privacidade mesmo passando o número do celular para } \\
\text { os alunos e conseguir, com eles, separar o lado pessoal do profissional }\end{array}$ \\
\hline XI. Dispersão & $\begin{array}{l}\text { - Constante inserção de temas ou assuntos alheios à discussão } \\
\text { proposta: é preciso sempre lembrar que deve haver concentração e foco } \\
\text { - A rapidez e fluidez do WhatsApp pode dificultar que o aluno } \\
\text { queira, depois, ler textos mais longos ou mais densos } \\
\text { - Requer comprometimento dos participantes para atividades em } \\
\text { grupo }\end{array}$ \\
\hline $\begin{array}{c}\text { XII. } \\
\text { Informalidade }\end{array}$ & $\begin{array}{l}\text { • Muitos usuários não têm clareza ou objetividade na escrita, e é } \\
\text { grande o risco de mal entendidos } \\
\text { - É difícil manter a disciplina e exigir o cumprimento de regras em } \\
\text { grupos virtuais } \\
\text { - É difícil avaliar os alunos em grupos de WhatsApp: a quantidade } \\
\text { de postagens não significa qualidade } \\
\text { - Normalmente há mais quantidade de informação do que de } \\
\text { conteúdo relevante } \\
\text { - Os alunos nem sempre entendem que o aplicativo pode ser } \\
\text { usado para aprender, não só para conversar ou se divertir }\end{array}$ \\
\hline
\end{tabular}

Fonte: dos autores. 2016.

Entre estas características destacam-se aquela que chamamos Aumento das atividades do professor e também a possível Dispersão de atenção dos estudantes quando utilizam esta tecnologia.

Vários professores afirmaram que o WhatsApp pode levar a um aumento das atividades, pois estudantes enviam mensagens durante o dia, noite e mesmo nos fins de semana. E o celular pode também aumentar a dispersão dos alunos na medida em que estes 
têm acesso não somente ao trabalho solicitado na aula, mas a muitos sites e conversas com amigos e colegas. Assim, eles podem se dispersar das tarefas propostas.

\section{CONSIDERAÇÕES FINAIS}

Reflexões teóricas e análises de práticas pedagógicas conjugam-se nesta pesquisa para responder à pergunta norteadora: "Quais são as vantagens e os desafios apresentados por professores que utilizam o aplicativo WhatsApp como suporte pedagógico?". Os resultados mostram que têm razão os professores que afirmam serem as relações entre tecnologia e ensino muito mais complexas do que alguns estudos podem fazer supor. No entanto, independentemente do grau de complexidade, é possível concluir que mesmo não havendo um modo único de utilizar determinado recurso, o importante é trabalhar com coerência em relação ao que se acredita serem escolhas acertadas.

Entre os participantes da pesquisa, os professores que se adaptam e preocupam-se em acompanhar o tempo e as demandas dos alunos se mostraram bastante preparados para agregar valor às suas práticas de ensino. Pôde-se perceber que, quanto menos alheios às transformações sociais da contemporaneidade, mais esses profissionais têm facilidade de promover processos de ensino e aprendizagem que sejam, de fato, efetivos, dinâmicos e colaborativos. Ou seja, os resultados mostraram-se convergentes.

No grande desafio de captar diferentes visões sobre o uso do WhatsApp como ferramenta pedagógica com os professores que participaram do questionário online e/ou das entrevistas, vale destacar que as escolhas sobre o que descrever em cada trecho foram cuidadosas, mas, sobretudo, difíceis. Ao mesmo tempo em que havia relatos parecidos e que não conviria serem repetitivos, cada um representava uma história, uma trajetória profissional distinta.

Optou-se, então, por descrever detalhadamente pontos positivos e negativos desse uso, já que muitos professores, mesmo seguros de estarem realizando um trabalho apropriado, manifestaram, em alguns momentos, dúvidas ou dificuldades quanto ao uso de tecnologias em sala de aula. Entre as vantagens de utilizar o aplicativo com os alunos, os tópicos citados de forma recorrente foram: ser atrativo, ser colaborativo, permitir um trabalho contínuo, ser econômico, ser estimulante, proporcionar a comunicação de forma instantânea e dar diferentes oportunidades de um uso conveniente. 
Já entre os pontos negativos, tratados como "pontos de atenção", destacam-se: gerar aumento da carga de trabalho (especialmente porque requer tempo para ler as mensagens); exigir uma conectividade nem sempre possível para todos os participantes; representar desafios como o de lidar com meios que são mais conhecidos entre os alunos do que entre os professores; causar dispersão e ser informal.

Muitos professores relataram que aprenderam coisas novas com os alunos durante as atividades realizadas pelo WhatsApp. E não só nas questões de ordem prática quanto à tecnologia, especificamente, mas também a partir de reflexões, que se tornaram mais recorrentes e fluidas com as possibilidades de participação trazidas pelo ambiente virtual. Ficou evidente ainda que, como qualquer trabalho pedagógico, o uso do WhatsApp com os alunos requer estratégias e, sobretudo, planejamento. Não parece ser possível realizar uma atividade com resultados positivos, a partir do aplicativo, sem sair do lugar de grande detentor de conhecimentos para se colocar como mediador de grupos. Ou sem organizar previamente o tempo e os materiais que serão despendidos. E, ainda, sem propor objetivos claros a serem alcançados.

Aos nativos digitais é preciso oferecer mais do que conteúdos curriculares. Para conquistá-los, o professor precisa oferecer aulas e atividades atrativas, lúdicas, divertidas e que tragam algo novo em relação as vivências que eles já têm. Muitos alunos, inclusive, mostram dificuldade de discernir a hora de falar sério por meio do aplicativo da hora de poder brincar, como é comum no WhatsApp. Mas até isso pode ser visto pelos professores como ensinamento importante de ser passado para a vivência dos estudantes.

Foi possível perceber, ao longo dos últimos meses, que a aproximação propiciada pela comunicação via WhatsApp acaba mudando até a postura de alguns profissionais. Vários deles usaram uma linguagem visivelmente leve nas entrevistas. A colaboração, em seu sentido estrito, foi percebida em vários momentos desta pesquisa. Alguns participantes deram dicas de leituras, mencionaram usos do WhatsApp que esta pesquisadora ainda não sabia serem viáveis, além de possíveis desdobramentos e derivações para outras ferramentas tecnológicas, como a substituição do uso do WhatsApp pelo Google Classroom, por exemplo.

Nota-se que foi por causa do poder de capilaridade do aplicativo que se chegou a tal diversidade de profissionais pesquisados. O envio do convite para responder o questionário on-line, por e-mail, redes sociais e pelo próprio WhatsApp, mostrou a dinâmica da 
amostragem Bola de Neve e também o interesse que o tema desperta em pessoas tão diferentes, que vivem nas mais diversas regiões do país. Assim, chegamos a professores jovens e experientes; focados, antenados ou dispersos; que trabalham em grandes cidades ou em escolas rurais do interior do país.

Dessa forma, enxergar pelo viés positivo o cenário educativo como desafiador e dinâmico tornou-se uma tarefa engrandecedora. Este estudo busca, então, o mérito de deixar os professores - leitores deste trabalho - mais hábeis quanto às vantagens e desvantagens do uso pedagógico do WhatsApp. Sobretudo, busca deixar esses profissionais mais conscientes do papel que devem desempenhar frente aos alunos dos dias de hoje. Não é uma questão simples, tampouco passível de respostas únicas ou acabadas. Mas esta é uma construção ambiciosa e profunda da qual qualquer pesquisador pode se orgulhar de poder contribuir. Porque, como disse o grande mestre inspirador Paulo Freire, "o mundo não é / o mundo está sendo".

\section{REFERÊNCIAS}

ANATEL, Agência Nacional de Telecomunicações. Aparelhos celulares no Brasil. 2016. Disponível em: Disponível em: <http://www.anatel.gov.br>. Acesso em: 11 fev. 2017, 09:18:35.

BALDIN, N.; MUNHOZ, E. M. B.. Educação ambiental comunitária: uma experiência com a técnica de pesquisa snowball (bola de neve). Revista Eletrônica Mestrado em Educação Ambiental, Rio Grande, RS, v. 27, p. 46-60, jul/dez, 2001. Disponível em: <http://www.seer.furg.br/remea/article/view/3193>. Acesso em: 13 fev. 2017, 13:25:56. EISSN: 1517-1256.

BARCELLOS, R. da S. de.. O uso do WhatsApp na aula de LP. In: II CONGRESSO NACIONAL DE EDUCAÇÃO - CONEDU. Trabalhos. Campina Grande, PB: CONEDU, 2015. Disponível em: $<$ http://www.editorarealize.com.br/ revistas/conedu/trabalhos/TRABALHO_EV045_MD1_SA15_ID3019_23072015200450.pdf>. Acesso em: 13 fev. 2017, às 08:47:24.

BAUER, M. W. (org.) Análise de conteúdo clássica: uma revisão. In: BAUER, M. W; GASKELL, G.. Pesquisa qualitativa com textos, imagem e som: um manual prático. Petrópolis: Vozes, 2002.

BOTTENTUIT JUNIOR, J. B.; ALBUQUERQUE, O. C. P.. Possibilidades para o uso do WhatsApp na educação: análise de casos e estratégias pedagógicas. In: I SIMPÓSIO NACIONAL DE TECNOLOGIAS DIGITAIS NA EDUCAÇÃO. Anais do I Simpósio Nacional de Tecnologias Digitais na Educação. São Luís, MA: Universidade Federal do Maranhão, 
2016. Disponível em: <https://www.academia.edu/ 30089309/>. Acesso em 12 de fev. 2017, 10:28:56.

CASTELLS, M.. Redes de indignação e esperança. São Paulo: Zahar, 2013.

CETIC. BR. Pesquisas TIC 2015. Disponível em: http://cetic.br. Acesso em: 13 fev. 2017, $15: 23: 45$

CRESWELL, J. W. Projeto de pesquisa: métodos qualitativo, quantitativo e misto. 3. ed. Porto Alegre: Artmed, 2010.

GASKELL, G.. Entrevistas individuais e grupais. In: BAUER, M.. W; GASKELL, G.. Pesquisa qualitativa com textos, imagem e som: um manual prático. Petrópolis: Vozes, 2002.

HONORATO, W. de A. M.; REIS, R. S. F.. WhatsApp: uma nova ferramenta para o ensino. In: IV SIMPÓSIO DE DESENVOLVIMENTO, TECNOLOGIAS E SOCIEDADE SIDTECS. Anais do IV SIDTECS. Itajubá, MG: Universidade Federal de Itajubá, 2014. Disponível em: <http://www.sidtecs.com.br/ 2014/wp-content/uploads/2014/10/413.pdf>. Acesso em: 19 fev. 2016, 14:45:22.

JENKINS, H.. Cultura da convergência. São Paulo: Aleph, 2009.

LEMOS, A.. A comunicação das coisas: teoria ator-rede e cibercultura. São Paulo: Annablume, 2013.

LÉVY, P.. Cibercultura. Trad. Carlos Irineu da Costa. São Paulo: Editora 34, 1999.

LOPES, C. G.. O ensino de história na palma da mão: o WhatsApp como ferramenta pedagógica para além da sala de aula. In: SIMPÓSIO INTERNACIONAL DE EDUCAÇÃO À DISTÂNCIA - ENCONTRO DE PESQUISA EM EDUCAÇÃO À DISTÂNCIA - SIED-EnPED. Anais do SIED-EnPED. São Carlos, SP: UFSCar, 2016.

MORAN, J. M.. Educação híbrida: um conceito-chave para a educação hoje. In: BACICH, L.; TANZI NETO, A,; TREVISANI, F. de M.. Ensino híbrido: personalização e tecnologia na educação. Porto Alegre: Penso, 2015.

NAGUMO, E.; TELES, L. F. O uso do celular por estudantes na escola: motivos e desdobramentos. In: REVISTA BRASILEIRA DE ESTUDOS PEDAGÓGICOS (on-line). Brasília, v. 97, n. 246, p. 356-371, maio/ago. 2016. ISSN: 2176-6681.

PEREIRA, A. P.; ARAÚJO, A.. R. de. PIBID online: uso do WhatsApp como ferramenta Didática. In: V ENCONTRO DE INICIAÇÃO A DOCÊNCIA DA UNIVERSIDADE ESTADUAL DA PARAÍBA. Anais. João Pessoa: UEPB, 2015.

PROFESSOR D. Entrevista. Entrevista colhida via Skype. 30 minutos de duração. Mai. 2016.

PROFESSOR E. Entrevista. Entrevista colhida via Skype. 30 minutos de duração. Mai. 2016.

PROFESSOR F. Entrevista. Entrevista colhida via Skype. 30 minutos de duração. Mai. 2016. 
PROFESSOR G. Entrevista. Entrevista colhida via Skype. 30 minutos de duração. Mai. 2016.

SANTOS, G. L. Ensinar e aprender no meio virtual: rompendo paradigmas. In: Educação e Pesquisa, São Paulo, v. 37, n. 2, p. 307-320, maio/ago, 2011. Disponível em: $<$ http://www.scielo.br/scielo.php?pid=S1517-97022011000200007\& script=sci_arttext $>$. Acessado em: 10 jul. 2015, 16:15:45.

SERRES, M.. Polegarzinha. 2a ed. Rio de Janeiro: Bertrand Brasil, 2015.

SILVA, L. Ribeiro; TELES, L. F.. A colaboração online como agente de emancipação em redes sociais. Revista Artefactum - Revista de Estudos em Linguagem e Tecnologia. Ano VIII $-\mathrm{N}^{\circ}$ 02/2016. ISSN: 1984-3852.

SILVA, L. C. da H.; SILVA, J. C. F. da; RIBEIRO, M. M.. WhatsApp e a educação: uma ferramenta que pode contribuir para o ensino de biologia. In: III ENCONTRO REGIONAL DE BIOLOGIA - EREBIO. Anais do III EREBIO. Rio de Janeiro, 2015. Disponível em: <http://www.sbenbio.org.br/wordpress/wp-content/uploads/2015/06/ EIXO.2.CO.21.doc>. Acesso em: 19 fev. 2016, 22:57:28. 